\title{
SURGICAL MANAGEMENT OF TIBIAL PLATEAU FRACTURES USING MINIMALLY INVASIVE TECHNIQUE WITH LOCKING COMPRESSION PLATING
}

\author{
Mohammed Abdul Wahed ${ }^{1}$, P. N. Prasad², Ajay Kumar Pandey33, D. V. Srinath ${ }^{4}$ \\ 1 Professor, Department of Orthopaedics, Shadan Institute of Medical Sciences, Hyderabad. \\ 2 Professor, Department of Orthopaedics, Shadan Institute of Medical Sciences, Hyderabad. \\ ${ }^{3}$ Assistant Professor, Department of Orthopaedics, Shadan Institute of Medical Sciences, Hyderabad. \\ 4 Junior Resident, Department of Orthopaedics, Shadan Institute of Medical Sciences, Hyderabad.
}

\section{ABSTRACT}

\section{BACKGROUND}

The objective of this study is to study the functional outcome of internal fixation of tibial plateau fractures by minimally invasive locking compression plating.

\section{MATERIALS AND METHODS}

A prospective study of internal fixation of tibial plateau fractures fixed with locking compression plating using minimally invasive technique was conducted during the period from Nov. 2013 to Nov. 2015 at Shadan Institute of Medical Sciences, Hyderabad, T. S.

Study sample size - 20 patients both male and female aged 20 to 70 yrs. admitted for tibial plateau fractures and operated between Nov. 2013 and Nov. 2015 and fulfilling the inclusion criteria were enrolled in a prospective study of 2 years' duration from Nov. '13 to Nov.' 15 . The followup period was 6 to 18 months. All cases were post traumatic.

\section{RESULTS}

Minimally invasive procedure using locking compression plating for fixation of tibial plateau fractures gives good results, as there is less soft tissue damage and stable fixation and comparatively better functional outcome.

\section{CONCLUSION}

This surgical procedure is a better option for fixation of tibial plateau fractures in terms of overall functional results.

\section{KEYWORDS}

Tibial Plateau Fractures, Minimally Invasive Technique, Locking Compression Plate, Internal Fixation, Functional Outcome.

HOW TO CITE THIS ARTICLE: Wahed MA, Prasad PN, Pandey AK, et al. Surgical management of tibial plateau fractures using minimally invasive technique with locking compression plating. J. Evolution Med. Dent. Sci. 2016;5(99):7298-7302, DOI: $10.14260 /$ jemds/2016/1651

\section{BACKGROUND}

Management of tibial plateau fractures are being modified continuously, tibial plateau fractures are one of the common fractures because of exposure of lower limbs to trauma and its management is crucial because of weight bearing nature of lower limbs. Before deciding on the line of management keep in mind following facts:

1. Extent of damage in tibial plateau fractures is often greater than what is seen on $x$-ray.

2. Malunion is extremely common, whereas nonunion is unknown.

3. Painful knee and stiffness are the most serious and common complications of tibial plateau fractures.

The LCP is an example of new technology, which combines the principle of limited contact compression and locked internal fixation. The operative treatment of the fracture using plates and screws is a successful technique. Internal fixation with plates and screws leads to additional trauma and disturbance of blood supply to bone.

Financial or Other, Competing Interest: None.

Submission 03-11-2016, Peer Review 29-11-2016,

Acceptance 05-12-2016, Published 12-12-2016.

Corresponding Author:

Dr. Mohammed Abdul Wahed,

\#12-2-823/A/86,

Flat No. 301, Double Tree Apartments,

Santosh Nagar Colony, Mehdipatnam, Hyderabad-500028.

E-mail: wahed35@hotmail.com

DOI: $10.14260 /$ jemds/2016/1651
To overcome these difficulties, the recently developed locking compression plating is gaining popularity. The technology supports what is known as MIPPO. The LCP technology offers improved fixation stability in osteoporotic bone, comminuted and periarticular fractures. ${ }^{1}$

\section{Aims and Objectives}

1. To study the functional outcome of management of fractures of tibial plateau.

2. To study the duration to achieve the union in tibial plateau fractures treated with LCP.

3. To assess the range of motion of knee joint and functional outcome after surgical management.

\section{Review of Literature}

Fractures of tibial condyles were brought into prominence in 1929 by the papers of Cotton F. J. and Berg R. in Boston and Cubbins W. R., Seiffert G. and Coneley A. H. from Chicago.

In 1940 Barr J. S. described the operative treatment of tibial plateau fractures, where depressed plateau is elevated by spike and supported by cancellous bone grafts. ${ }^{2}$ In 1956, G. Apley published the series of patients treated by skeletal traction and early mobilisation with excellent results. ${ }^{3}$

In the meantime, different experimental studies were carried out. Haldeman K. O. in 1939 proved that hyaline cartilage is replaced by fibrocartilage. Hohl M. in 1956 proved that prolonged immobilisation leads to formation of intraarticular adhesions. 
A. G. Apley in 1956, Hohl M in 1956, Rasmussen P. S. in 1973 put forward the system of grading the results. ${ }^{4}$

Moore T. M. and Harvey J. P. in 1974 describing the plateau view of measuring the exact depression of tibial plateau. ${ }^{5}$

Many varieties of implants have been developed and used to fix the plateau fractures. Later A. O. (ASIF) described the surgical treatment to be mandatory for tibial plateau fractures.

Aim is to achieve anatomical reduction, rigid internal fixation and early mobilisation.

Wilsons and Jacobs in 1952 used the articular surface of the patella for replacing the severely depressed comminuted fractures of lateral condyle. ${ }^{6}$

Rasmussen S. Poul and Gothenberg in 1973, followed a series of 260 fractures of one or both condyles. The main indication of surgery was evidence of instability of extended knee. ${ }^{7}$

Schatzker and McBroom in 1979 considered that open reduction with anatomical restoration of articular cartilage provides best results. ${ }^{8}$

The operative treatment of fracture using plate and screws is a successful technique. Internal fixation with plate and screws leads to additional trauma and disturbance of blood supply to bones.

To overcome these difficulties, the recently developed locking compression plating is gaining popularity.

\section{Surgical and Applied Anatomy}

Fracture patterns in proximal tibia are dictated by the forces applied combined with the osseous anatomy of proximal tibia. Occasionally, muscle forces or ligament attachments play a part in the fracture pattern.

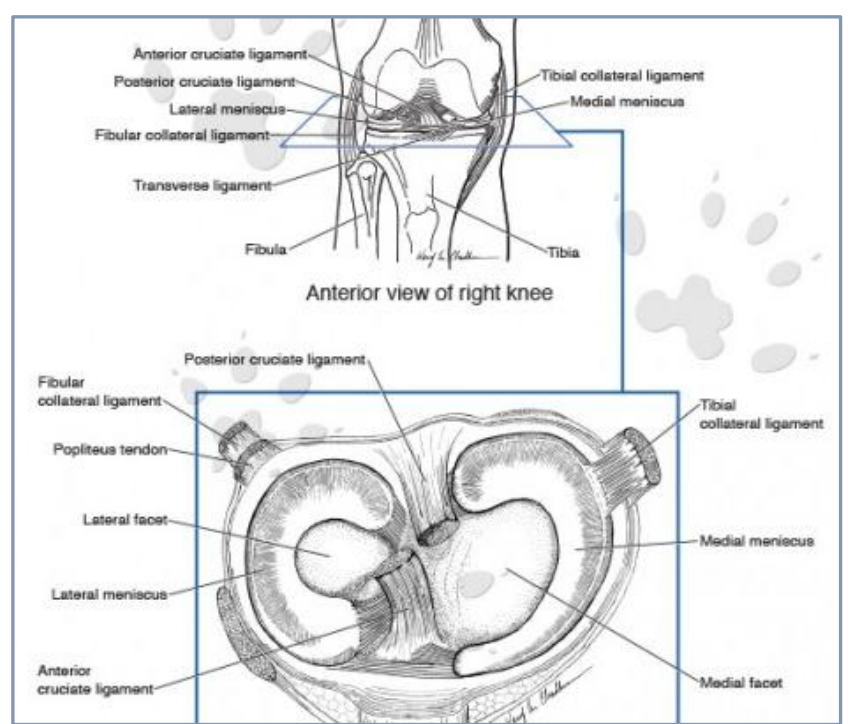

\section{Gross Anatomy}

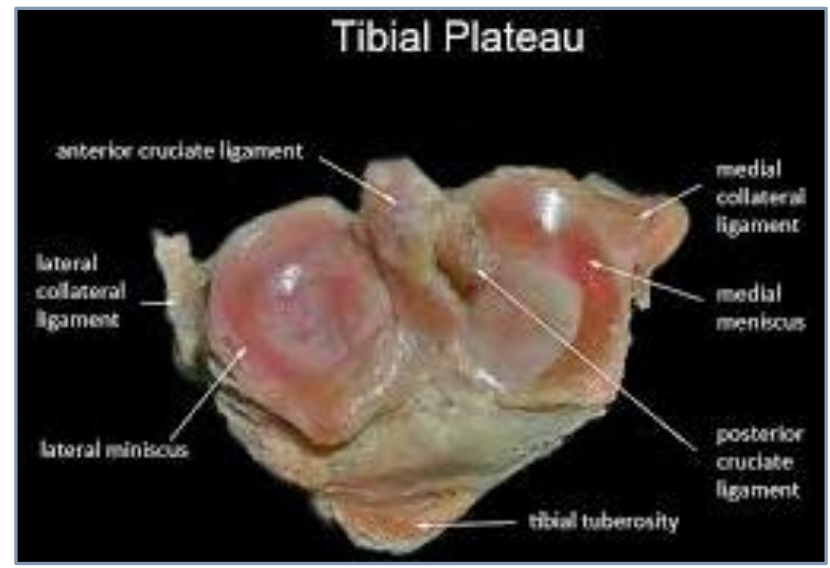

Schatzker's Classification

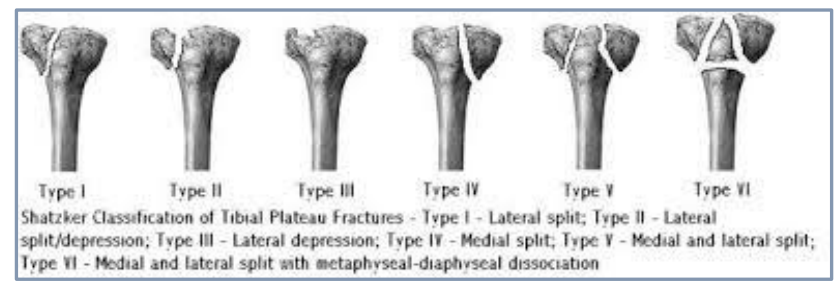

\section{Mechanism of Injury}

Tibial plateau fractures are intra-articular fractures of proximal tibia with the highest incidence in the $3^{\text {rd }}$ to $5^{\text {th }}$ decades of life.

The magnitude, type and direction of forces that injure the knee dictate the fracture pattern, the greater the energy absorbed by the proximal tibia the more severe is the fracture and more the fragments are displaced and comminuted. ${ }^{9}$ Generally, axial loading forces are more rapid and release greater energy than angular forces.

Tibial plateau fractures also have typical local soft tissue injuries that are important to recognise, because they may influence management and prognosis. Associated intraarticular soft tissue injuries to both cruciate ligaments and menisci play a role in managing tibial plateau fractures. ${ }^{10}$
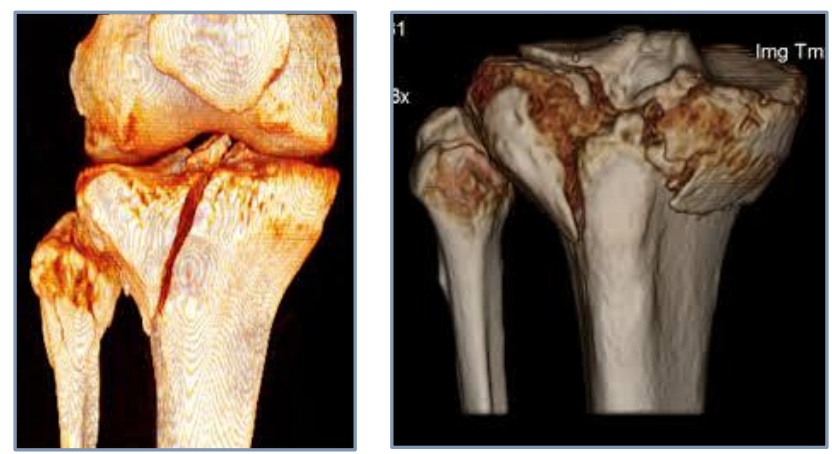

Posterior View of Specimen Anterior View 

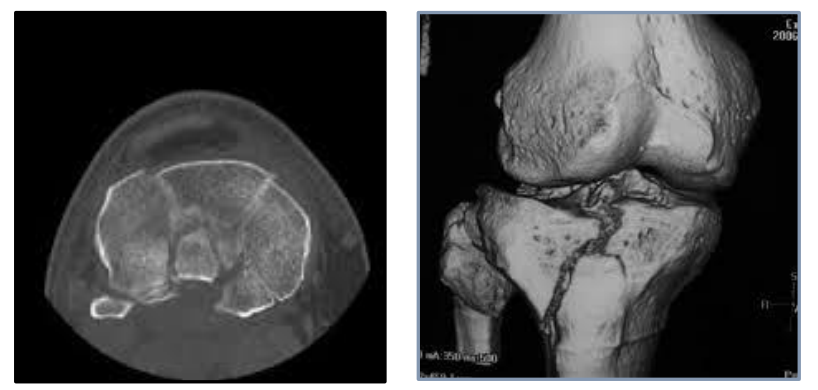

CT-Image of Fracture Anterior View

\section{MATERIALS AND METHODS}

A prospective study on tibial plateau fracture fixation with locking compression plating using minimally invasive technique was conducted in the period from November 2013 to November 2015.

\section{Study Area}

Shadan Institute of Medical Sciences, Hyderabad, T. S.

\section{Study Population}

All male and female patients aged 20 to 70 years admitted in the hospital.

\section{Study Sample Size}

Twenty patients who were admitted and operated between Nov. 2013 and Nov. 2015 and had fulfilled the inclusion criteria were enrolled for the study.

\section{Duration of Study}

Nov. 2013 to Nov. 2015 (2 years).

Followup ranged from 6 to 18 months.

All the fractures were post-traumatic.

\section{Inclusion Criteria}

1. The patients with tibial plateau fractures (Schatzker classification).

2. Age 20 to 70 years.

3. Patients with Gustilo-Anderson type 1 and 2 tibial plateau fractures.

\section{Exclusion Criteria}

1. Patients with pathological fractures.

2. Gustilo-Anderson type 3 tibial plateau fractures.

3. Associated segmental tibial fractures with plateau fractures.

4. Ipsilateral femoral fractures.

5. Children before closure of epiphyses.

6. Gross comorbid conditions.

\section{General Principles for using LCP11}

Conventional compression plating needs good bone quality and precise anatomical reduction. In multi-fragmentary shaft fractures, precise anatomical reduction is often not possible without a great risk of an iatrogenic soft tissue trauma. The primary and the secondary loss of reduction leading to malalignment and instability. Conventional plating leads to compression of the periosteum, which causes a disturbance of the blood supply. Plate and screw systems where the screw can be locked in the plate form, one stable system and the stability of the fracture depends on the stiffness of the construct.

No compression of the plate on the bone is required to suppress the risk of primary loss of reduction and preserve the blood supply. Locking the screws in the plate ensures both angular as well as axial stability and eliminates the possibility of the screw to toggle, slide or be dislodged.

The LCP with combination holes allows the surgeons to use it as a conventional plate as well as an internal fixator with locking head screws. There are different indications to use LCP for different techniques and biomechanical principles.

Locking Compression Plate and Screws: Implants LCP screw. Hockey stick, buttress plate, LCP.

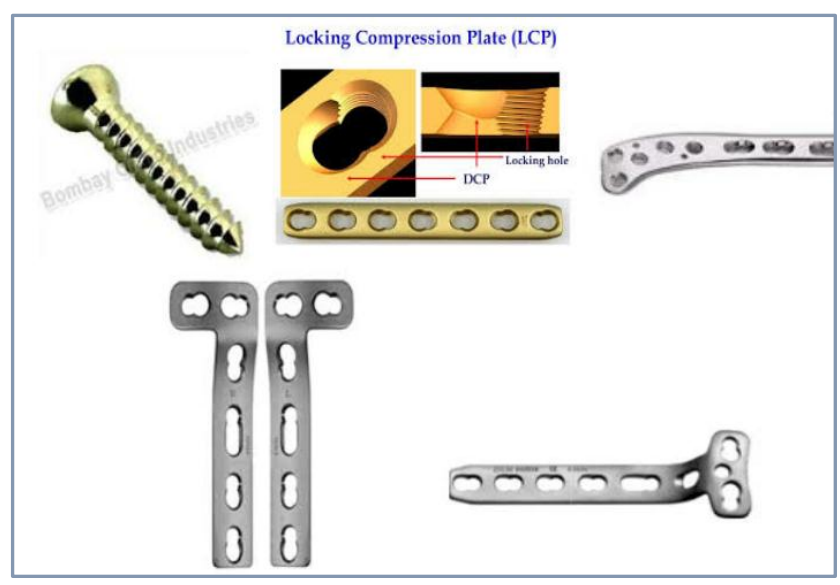

Locking L-Plate Locking Buttress Plate

\section{Surgical Procedure}

Minimally Invasive Percutaneous Plate Osteosynthesis (MIPPO) with Locking Compression Plate for Tibial Plateau Fractures

All surgeries were performed on an elective basis using standard procedures under spinal or general anaesthesia. In supine position, ipsilateral iliac crest was prepared and draped for possible autogenous bone grafting. Fracture was reduced indirectly under $\mathrm{C}$-arm guidance by using a proximal pin in the distal femur and a distal pin in tibia distal to fracture; $2 \mathrm{~mm} \mathrm{~K}$ wires were used as joy stick to reduce and hold fracture fragments. Temporary fixation was done with K-wires.

An incision of 2 to $3 \mathrm{cms}$ over proximal aspect of tibia over the medial or lateral side (depending on the fracture pattern) was taken. A submuscular plane was created and a precontoured stainless steel $4.5 \mathrm{~mm}$ locking compression plate was slid in the anterior submuscular plane. The plate was held in place by K-wires. It was then fixed with screws, which were inserted percutaneously through the primary surgical incisions. Distally, $3.2 \mathrm{~mm}$ drill bit was used for drilling and 4.5 mm cortical screws were inserted and fixed. Reduction was satisfactory and wound closed. 


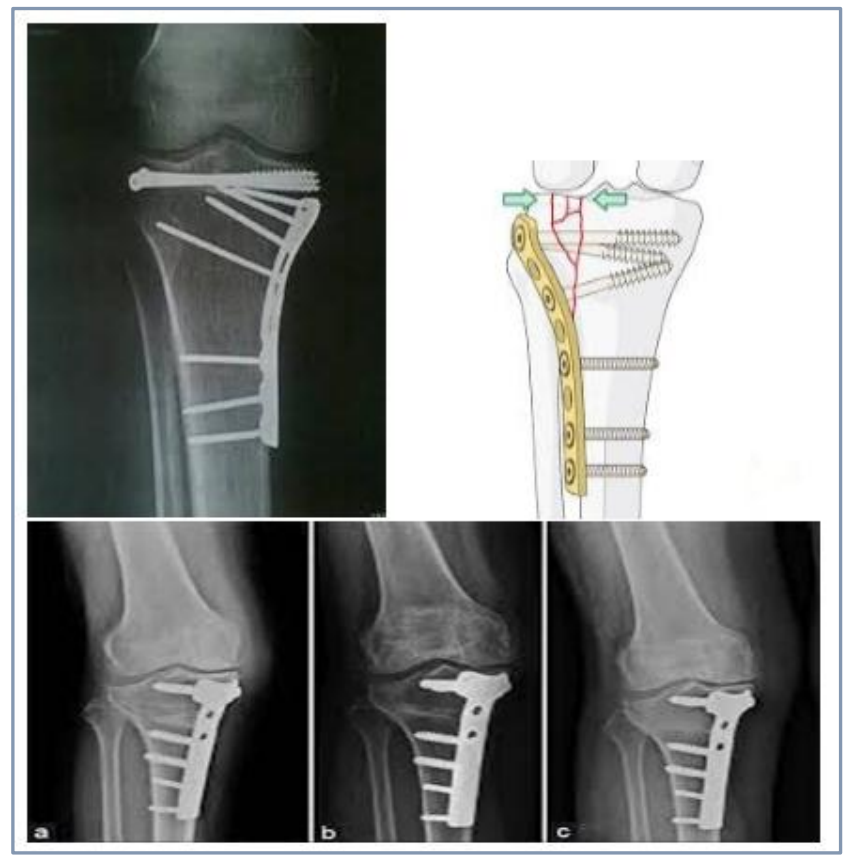

Post-Operative X-Rays and Schematic Diagram of LCP

\section{Mobilisation}

Splints are removed and mobilisation of the limb started on the $3^{\text {rd }}$ or $4^{\text {th }}$ postoperative day. Mobilisation with non-weight bearing was started from the first post-operative week till 6 to 8 weeks.

Depending on the fracture pattern and then partial weight bearing after confirmation of beginning of healing process till fracture union.

Follow-up: At the time of discharge the patients were asked to come for follow-up after 6 weeks and for further follow-up at 3 months, 6 months and 1 year. The patients who turned for followup or whose details could be collected were finally taken up for the assessment of functional results.

At follow-up, patients were evaluated according to Neer's scoring system for pain, limp, the use of support, walking distance, ability to climb stairs, ability to squat and sit crosslegged, ability to put on shoes and socks sitting on chair, ability to enter the public transportation, deformities, leg length discrepancy and movements. The radiograph of operated tibial plateau was taken at regular intervals at each followup.

\section{RESULTS}

\begin{tabular}{|c|c|c|}
\hline Age (Years) & No. of Patients & Percentage \\
\hline $20-30$ & 06 & 30 \\
\hline $31-40$ & 06 & 30 \\
\hline $41-50$ & 06 & 30 \\
\hline $51-60$ & 01 & 5 \\
\hline $61-70$ & 01 & 5 \\
\hline TOTAL & 20 & 100 \\
\hline \multicolumn{3}{|c|}{ Table 1. Age Distribution } \\
\hline
\end{tabular}

\begin{tabular}{|c|c|c|}
\hline Sex & No. of Patients & Percentage \\
\hline MALE & 18 & 90 \\
\hline FEMALE & 2 & 10 \\
\hline \multicolumn{3}{|c|}{ Table 2. Sex Distribution } \\
\hline
\end{tabular}

\begin{tabular}{|c|c|c|}
\hline Mechanism of Injury & No. of Cases & Percentage \\
\hline $\begin{array}{c}\text { ROAD TRAFFIC } \\
\text { ACCIDENT }\end{array}$ & 17 & 85 \\
\hline FALL FROM HEIGHT & 03 & 15 \\
\hline TOTAL & 20 & 100 \\
\hline \multicolumn{2}{|c|}{ Table 3. Mechanism of Injury } \\
\hline
\end{tabular}

\begin{tabular}{|c|c|c|}
\hline Schatzker & No. of Cases & Percentage \\
\hline TYPE-1 & 01 & 5 \\
\hline TYPE-2 & 11 & 55 \\
\hline TYPE-3 & 0 & 0 \\
\hline TYPE-4 & 08 & 40 \\
\hline TYPE-5 & 0 & 0 \\
\hline TYPE-6 & 0 & 0 \\
\hline \multicolumn{3}{|c|}{ Table 4. Classification } \\
\hline
\end{tabular}

\begin{tabular}{|c|c|c|}
\hline $\begin{array}{c}\text { Hospital Stay } \\
\text { (Days) }\end{array}$ & No. of Patients & Percentage \\
\hline $10-15$ & 14 & 70 \\
\hline $15-20$ & 4 & 20 \\
\hline$>20$ & 2 & 10 \\
\hline \multicolumn{3}{|c|}{ Table 5. Hospital Stay } \\
\hline
\end{tabular}

\begin{tabular}{|c|c|c|}
\hline Union (Weeks) & No. of Cases & Percentage \\
\hline$<14$ & 03 & 15 \\
\hline $14-16$ & 07 & 35 \\
\hline $16-18$ & 06 & 30 \\
\hline $18-20$ & 04 & 20 \\
\hline \multicolumn{3}{|c|}{ Table 6. Time to Union } \\
\hline
\end{tabular}

\begin{tabular}{|c|c|c|}
\hline $\begin{array}{c}\text { Achieved Times } \\
\text { (Weeks) }\end{array}$ & No. of Cases & Percentage \\
\hline$<16$ & 04 & 20 \\
\hline $16-18$ & 08 & 40 \\
\hline $18-20$ & 05 & 25 \\
\hline $20-22$ & 03 & 15 \\
\hline \multicolumn{2}{|c|}{ Table 7. Full Weight Bearing Achieved } \\
\hline
\end{tabular}

\begin{tabular}{|c|c|c|}
\hline $\begin{array}{c}\text { Knee Flexion } \\
\text { (Degrees) }\end{array}$ & No. of Cases & Percentage \\
\hline$<90$ & 03 & 15 \\
\hline $91-119$ & 06 & 30 \\
\hline$>120$ & 11 & 55 \\
\hline \multicolumn{3}{|c|}{ Table 8. Knee Flexion } \\
\hline
\end{tabular}

\begin{tabular}{|c|c|c|}
\hline Complication & No. of Cases & Percentage \\
\hline Stiffness & 08 & 40 \\
\hline Delayed Union & 02 & 10 \\
\hline Infection & 01 & 10 \\
\hline Knee Pain & 04 & 20 \\
\hline Skin Necrosis & 00 & 00 \\
\hline Implant Failure & 00 & 00 \\
\hline Implant Exposure & 00 & 00 \\
\hline \multicolumn{2}{|c|}{ Table 9. Complications } \\
\hline
\end{tabular}

\begin{tabular}{|c|c|c|}
\hline Rating (Points) & No. of Cases & Percentage \\
\hline Excellent $(>85)$ & 30 & 6 \\
\hline Good $(70-85)$ & 60 & 12 \\
\hline Fair $(55-69)$ & 5 & 1 \\
\hline Poor $(<55)$ & 5 & 1 \\
\hline \multicolumn{3}{|c|}{ Table 10. Rating } \\
\hline
\end{tabular}




\section{DISCUSSION}

This study comprised of twenty patients. Overall functional outcome was assessed in terms of regaining. Lost knee function using Neer's score.

The advent and development of locking compression plating method has effectively improved management of tibial plateau fractures as common complex fractures. The present study shows good results. This superiority seems to be preserved in terms of other parameters including ROM index, function score, bone graft need and even post-operative complications.

Stannard and Colleagues collected data from a series of 39 cases, all of which healed without further intervention and with only two superficial infections. ${ }^{12}$

Cole et al reported the results of 42 consecutive tibial plateau fractures with $91 \%$ union, $9 \%$ mal-alignment and $4 \%$ infection rate. 13

Krupp et al found that locked plating was associated with a decreased time to union, decreased incidence of articular malunion, decreased knee stiffness and decreased overall complications. ${ }^{14}$

In the present study we preferred Schatzker classification, because it is simple and no special x-rays are required. Its practical utility to carry out treatment and prognosis assessment has got an upper hand.

According to Muller M.E., Allgower and Willenger, depressed type of fractures are very commonly associated with ligamentous injury $20 \%$.

Diagnosis of ligamentous injuries should be made at the earliest to prevent residual disabilities.

\section{CONCLUSION}

1. Locking compression plating is a good fixation system for tibial plateau fractures.

2. Operative time is certainly reduced with minimal invasive technique and the soft tissue damage is considerably less.

3. The device provides good angular stability and helps in early mobilisation. Thus locking compression plate is an optimal tool for tibial plateau fracture management. Minimal invasive technique under guidance of image intensifier provides better plate placement.

\section{REFERENCES}

1. Egol KA, Koval KJ. Fractures of proximal tibia. Chapter 50, Rockwood and Greens. "Fractures in adults. Vol 2, 6 ${ }^{\text {th }}$ edn. Lippincot Williams and Wilkins 2006.
2. Duparc, Ficat. Fracture of the tibial plateau in Insall et al surgery of the knee. 2nd edn. New York, Churchill Livingstone 1995;2:1074.

3. Apley AG. Fractures of lateral tibial condyle treated by skeletal traction and early mobilization. JB \& JS 1956;38(3):699-708.

4. Bowes DN, Hohl M. Tibial condylar fractures. Evaluation of treatment and outcome. Clin Orthop Relat Res 1982;171:104-8.

5. Moore TM, Harvey JP. Roentgenographic measurement of tibial plateau depression due to fractures. JB \& JS 1974;56(1):155-60.

6. Wilson JN. Injuries of the knee in Watson-Jones and joint injuries. Vol-2, $6^{\text {th }}$ edn. New Delhi. B. I. Churchill Livingstone 2002;1077-9.

7. Rassmussen PS. Tibial condylar fractures. Impairment of knee joint stability as an indication for surgical treatment. J Bone and Joint Surg 1973;55(7):1331-50.

8. Schatzker J, McBroom R, Bruce D. The tibial plateau fractures. The toronto experience 1968-1975. Clin Orthop Relat Res 1979;138:94-104.

9. Whittle AP, George W. Wood II. Fracture of proximal tibia (Tibial plateau). $10^{\text {th }}$ edn. In: Canale ST. edt. Campbell's Operative Orthopaedics 2005:2783-96.

10. Wilppula E, Bakalim G. Ligamentous tear concomitant with tibial condylar fracture. Acta Orthop Scand 1972;43(4):292-300.

11. Wagner M. General principles for the clinical use of LCP. Injury 2003;34(2):B31-42.

12. Stannard JP, Wilson TC, Volgas DA, et al. The less invasive stabilization system in the treatment of complex fractures of tibial plateau. Short term results. J Orthop Trauma 2004;18(8):552-8.

13. Cole PA, Zlowodzki M, Kregor PJ. Treatment of proximal tibial fractures using the less invasive stabilization system: surgical experience and early clinical results in 77 fractures. Journal of Orthopedic Trauma 2004;18(8):52835.

14. Krupp RJ, Malkani AL, Roberts CS, et al. Treatment of bicondylar tibial plateau fractures using locked plating versus external fixation. Orthopedics 2009;32(8):559. 